\title{
A GEOGRAFIA DOS CRIMES VIOLENTOS EM UBERLÂNDIA-MG
}

\author{
GEOGRAPHY OF VIOLENT CRIMES IN UBERLÂNDIA-MG \\ GEOGRAFÍA DE DELITOS VIOLENTOS EN UBERLÂNDIA-MG
}

\section{Márcia Andréia Ferreira Santos}

Doutorado em Geografia pela Universidade Federal de Uberlândia. Desenvolve pesquisas na área de Geografia do Crime, com ênfase em violência urbana, vulnerabilidade à violência e territórios do crime. Universidade Federal de Uberlândia (UFU). Instituto de Geografia. Av. João Naves de Ávila, 2121 - Santa Mônica, Uberlândia - MG, 38408-100.

E-mail:marciaufu@yahoo.com.br

\section{RESUMO}

Este artigo apresenta uma análise dos crimes violentos em Uberlândia-MG, registrados entre 1999 e 2010 . Os procedimentos metodológicos basearam-se em levantamento de dados junto à Polícia Militar e pesquisa bibliográfica sobre o tema. Verificou-se o registro de 67.760 crimes violentos, dos quais 67.578 (99,73\%) totalizaram os estupros, homicídios e roubos. Estes representaram $97,88 \%$ do total de crimes. Os demais casos, constituídos de 182 eventos (0,27\%), foram os crimes de extorsão mediante sequestro, latrocínio, sequestro e cárcere privado. As ocorrências se destacaram no Centro (roubos) e São Jorge (estupros e homicídios). O aumento dos crimes violentos em Uberlândia e a persistência de certas modalidades criminais em alguns bairros levou as autoridades locais a implementar ações de combate e prevenção dos mesmos, implantando o Sistema Olho Vivo e ampliando o Projeto Fica Vivo, respectivamente de combate e prevenção aos roubos e homicídios, com resultados satisfatórios.

Palavras-chave: Crime violento, Homicídio, Roubo, Estupro, Geografia do Crime

\section{ABSTRACT}

This article presents an analysis of violent crime in Uberlandia, Minas Gerais, recorded between 1999 and 2010. The methodological procedures were based on data collection by the military police and literature on the subject. There was a record of 67,760 violent crimes, of which 67,578 (99.73\%) reached the rapes, murders and robberies. This represented $97.88 \%$ of the total crimes. The remaining cases, made up of 182 events $(0.27 \%)$ were the crimes of extortion through kidnapping, armed robbery, kidnapping and false imprisonment. The events stood out in the center (theft) and St. George (rape and murder). The increase in violent crimes in Uberlândia and the persistence of certain criminal procedures in some neighborhoods led local authorities to implement actions to combat and prevent thereof, deploying Eye System Living and expanding the Staying Alive Project respectively to combat and prevent the theft and murders, with satisfactory results.

Keywords: Violent Crime, Homicide, Robbery, Rape, Geography of Crime 


\section{RESUMEN}

En este artículo se presenta un análisis de los delitos violentos en Uberlandia, Minas Gerais, registrado entre 1999 y 2010. Los procedimientos metodológicos se basan en la recopilación de datos por la policía militar y la literatura sobre el tema. Hubo un récord de 67,760 crímenes violentos, de los cuales 67.578 (99,73\%) alcanzaron las violaciones, asesinatos y robos. Esto representó 97,88\% del total de delitos. Los casos restantes, compuestos de 182 eventos (0,27\%) fueron los delitos de extorsión mediante secuestro, robo a mano armada, secuestro y detención ilegal. Los eventos se destacaron en el Centro (robo) y San Jorge (violación y asesinato). El aumento de los delitos violentos en Uberlândia y la persistencia de ciertos procedimientos penales en algunos barrios llevaron a las autoridades locales para implementar acciones para combatir y prevenir la misma, el despliegue del Sistema Olho Vivo y ampliar el Projeto Fica Fivo, respectivamente, para combatir y prevenir el robo y asesinatos, con resultados satisfactorios.

Palabras clave: Crímenes Violentos, Homicidio, Robo, Violación, Crimen Geografía 


\section{INTRODUÇÃO}

Este artigo objetiva-se a discutir os crimes violentos registrados na cidade de Uberlândia entre 1999 e 2010. Para isso, foram levantadas informações nos Boletins de Ocorrência da Polícia Militar sobre os crimes violentos verificados no período, a saber: homicídio, estupro, extorsão mediante sequestro, latrocínio, roubo à mão arma, roubo sem arma, sequestro e cárcere privado. Este estudo destacou os roubos, homicídios e estupros, por terem sido os crimes de maior incidência no período em Uberlândia.

\section{A GEOGRAFIA DO CRIME E 0 ESTUDO DOS CRIMES VIOLENTOS}

Os crimes violentos são aqueles que intentam contra a vida, a integridade física e o patrimônio. São classificados em: crimes contra o patrimônio (propriedade) e crimes contra a pessoa. Conforme o Código Penal Brasileiro (Brasil, 1940) são considerados crimes violentos: homicídios e estupros tentados e consumados, extorsão mediante sequestro ${ }^{1}$, latrocínio ${ }^{2}$, roubo à mão arma, roubo sem arma, sequestro e cárcere privado ${ }^{3}$. No Art. 14 do Código Penal, diz-se crime consumado quando nele se reúnem todos os elementos de sua definição legal; e tentativa quando, iniciada a execução, não se consuma por circunstâncias alheias à vontade do agente. O parágrafo único do referido artigo declara que a punição da tentativa de crime se dá com a imputação da pena correspondente ao crime consumado, diminuída de um a dois terços.

A criminalidade violenta é uma temática que vem sendo trabalhada há algum tempo por diversas ciências, como o Direito, a Antropologia, a Sociologia. Todavia, no campo geográfico, especialmente no Brasil, passou a ser discutida sobretudo a partir da década de 1980. Um importante trabalho nesse campo foi desenvolvido pela geógrafa Rosa Maria Ramalho Massena, em 1986, intitulado: Distribuição espacial da criminalidade violenta na região metropolitana do Rio de Janeiro, publicado na Revista Brasileira de Geografia. Nele, a autora estuda a distribuição de quatro tipos de crimes: homicídio doloso consumado e tentado, estupro, lesão corporal e roubo, e justifica a sua escolha afirmando que tais crimes representavam, na época, 31,62\% do total de crimes registrados na Região Metropolitana do Rio de Janeiro, entre 1977 e 1980. Outra justificativa era de que tais crimes desencadeavam insegurança e medo na população.

\footnotetext{
Extorsão mediante sequestro (Art. 159): Sequestrar pessoa com o fim de obter, para si ou para outrem, qualquer vantagem, como condição ou preço do resgate, sendo a pena a reclusão de oito a quinze anos;

2 Latrocínio é o roubo seguido de morte. Não é tratado de forma separada no Código Penal Brasileiro, como os demais crimes citados, mas dentro da categoria "roubos" que, resultando em morte, a reclusão é de vinte a trinta anos, sem prejuízo da multa.

3 Sequestro e cárcere privado (Art. 148): Privar alguém de sua liberdade, mediante sequestro ou cárcere privado, sendo a pena configurada em reclusão de um a três anos.
} 
Massena (1986) comenta que na década de 1980 alguns estudiosos já desenvolviam trabalhos dentro da corrente da geografia do crime e/ou da violência, considerados assim pelo fato de os seus estudos tratarem da expressão espacial do crime. Ela ressalta que há um ponto em comum no estudo da criminalidade realizado por geógrafos e sociólogos, sendo, todavia, evidente que cada área segue um fundamento teórico e uma metodologia específica, apresentando, portanto, abordagens diferentes. Citando Georges ${ }^{4}$ (1978), ela afirma que ambas as áreas estão, em grande medida, embasadas na Teoria Ecológica da Escola de Chicago, como também em autores que são tributários dela, com novos argumentos e métodos. O referido autor acrescenta que

[...] a geografia do crime ao tentar mapear a distribuição espacial do crime, deve relacionar os padrões espaciais do crime às variáveis ambientais, sociais, históricas, psicológicas (cognitivas) e econômicas e dessa forma tentar melhor apreender a manifestação espacial do crime (Georges, 1978 apud Massena, 1986, p. 287).

Massena (1986) relata que os estudos desenvolvidos na perspectiva da geografia do crime, à época, eram realizados metodologicamente em dois níveis: 1) A partir da microanálise, com o objetivo de pesquisar o local onde ocorreu o crime, com vistas ao estabelecimento de relações entre ele e a dinâmica sociocultural do crime; 2) Por meio da macroanálise, que agregava os dados por áreas como favelas, subúrbios, área central de negócios, municípios etc., com o objetivo de estabelecer uma interpretação interespacial e interpessoal do crime. Hoje, os artigos, dissertações e teses produzidos na Geografia brasileira enquadram-se nesta perspectiva apresentada pela autora, todavia evoluindo para outras temáticas que naquela época ainda não eram tão exploradas como atualmente, o que pode estar relacionado ao período histórico e às mudanças ocorridas que necessitam de outras abordagens teóricas e de novas formas de análise.

O interesse pelos estudos geográficos tendo como enfoque a violência surgiu da necessidade de explicar e compreender a influência desse fenômeno na produção, configuração e reestruturação dos espaços urbanos, bem como na mudança de comportamento da população frente à percepção de aumento da criminalidade violenta e da insegurança. Observou-se, sobretudo a partir da década de 1990, que modificações nos estilos de vida e moradia e a preocupação com a segurança patrimonial e pessoal tornaram-se mais intensas, e muitas dessas questões tinham como influência o crescimento da violência, do medo e da insegurança nas cidades.

GEORGES, Daniel E. The geography of crime and violence: a spatial and ecological perspective. Washington D.C: Association of American Geographers (Resource papers for college geography, v.78, n.1, 1978. 
Em relação ao medo e à insegurança decorrentes da criminalidade violenta, Felix (2009) ressalta:

O medo de ser vítima condiciona o nível de exposição ao risco [...]. Altas taxas de criminalidade em uma região podem indicar alta exposição ao risco em função de acentuada "sensação de segurança" dos moradores. Por outro lado, baixas taxas podem não indicar, necessariamente, um excesso de segurança, mas serem o resultado de uma "sensação de insegurança" que restringe acentuadamente as atividades e, por conseguinte, reduz o nível de exposição das pessoas ao risco (Felix, 2009, p. 157).

O medo está por toda parte, e acompanha a todos que cotidianamente saem de casa para realizar atividades rotineiras. Quem geralmente revela maior sensação de insegurança é, sobretudo, o morador das grandes cidades brasileiras, afeito a todo tipo de violência, quer simbólica, quer física. Nesse sentido, Morais (1990) afirma que a urbanização, acelerada pelo processo capitalista, criou um ambiente propício à violência. Não se pode mais falar em segurança. A vida na cidade grande é marcada por riscos a todo instante, e acrescenta:

[...] o medo é o pão cotidiano dos cidadãos. As casas não mais expõem suas fachadas românticas, pois cercam-nas muros muito altos [...]. As pessoas trafegam em seus automóveis com os vidros bem fechados para evitar abordagens perigosas em cruzamentos e semáforos e, dependendo de por onde andem a pé, sentem-se como se estivessem em plena prática da 'roleta russa' [...]. Temem-se igualmente tanto as ações criminosas dos assaltantes quanto as ações policiais, marcadas por igual ferocidade. E em parte alguma há segurança (Morais, 1990, p.12).

Paisagens do medo (2005) é uma obra do geógrafo Yi-Fu Tuan que trata das diferentes manifestações de medo no mundo no decorrer da história da humanidade, e dentre elas aquele específico das cidades. Neste livro, o autor comenta que a

\begin{abstract}
A cidade representa a maior aspiração da humanidade em relação a uma ordem perfeita e harmônica, tanto em sua estrutura arquitetônica como nos laços sociais. [Todavia, isso não é o que se tem observado, principalmente nas cidades ocidentais]. Por mais que a cidade tenha mudado com o correr do tempo, o conflito persiste entre o desejo por uma ordem socioestética e a realidade das massas vivendo em um mundo dinâmico, mas confuso (Tuan, 2005, p.231; 233).
\end{abstract}

A forma como as pessoas veem a cidade com a sua dinâmica e os seus elementos físicos difere do real, ou seja, "Uma cidade pode ter lindos edifícios e praças ordenadas e, no entanto, a impressão geral é de desordem” (Tuan, 2005, p.239). O referido autor comenta, ainda, que "Durante sua história a cidade tem sido oprimida pela violência e pela ameaça constante do caos” (Tuan, 2005, p. 251). Nas cidades medievais, por exemplo, “[...] 
quando a noite se aproximava, os próprios cidadãos reconheciam a necessidade de se recolher para a segurança de seus lares, deixando os becos escuros aos ladrões e aos imprudentes foliões". E acrescenta, ainda, que pelo fato de o crime na cidade de Londres do século XVIII ser um fenômeno corrente, após o escurecer os moradores ofereciam resistência em ir às ruas pouco iluminadas. Por esta razão, concorda-se com Tuan (2005, p.334) quando ele afirma que "O medo não é apenas uma circunstância objetiva, mas também uma resposta subjetiva", sendo também um fator de proteção e estabelecimento de laços entre as pessoas, uma vez que "Removidas as ameaças do meio ambiente, quer sejam as forças da natureza, quer inimigos humanos, a união da comunidade tende a enfraquecer" (Tuan, 2005, p.336). Em Roma ou Florença medieval, por exemplo, “[...] existia uma forte lealdade em cada bairro protegido [...] mas os laços eram forjados pela necessidade e pelo medo" (Tuan, 2005, p. 336).

Esteves (1999, p.40) argumenta que

\begin{abstract}
A insegurança e a ansiedade são sentimentos directamente ligados ao medo, pois são em parte consequência do mesmo. Tanto o medo, por um lado, como a insegurança e ansiedade, por outro, resultam de um mal-estar e de desconfiança em relação a determinada situação ou local que se percepcionam como potencialmente ou efectivamente perigosos. Esta percepção do espaço como realmente ou potencialmente perigoso para circular, residir ou frequentar, resulta de várias opiniões e comentários feitos por amigos, vizinhos e notícias da comunicação social, que vão contribuindo para formar e enriquecer a imagem mental que cada pessoa possui sobre determinadas áreas.
\end{abstract}

De acordo com Ferreira e Penna (2005), a violência é um fenômeno que se territorializa no espaço urbano por meio de relações sociais que expressam uma configuração geográfica e se estabelecem num momento histórico específico. Essa territorialização da violência se dá a partir da fixação de elementos que possibilitam o estabelecimento de ações capazes de modificar as condições ambientais e sociais, redefinindo o lugar a partir disso. Mas, apesar de estar presente em todos os lugares da cidade, a violência apresenta-se em maior ou menor intensidade em determinados locais, e é isso que define como a população percebe tal fenômeno. Uma das principais formas de sentir a violência é através da sensação de insegurança e medo que imperam em maior ou menor grau, de acordo com o local habitado. A violência apresenta uma dinâmica própria no espaço, sendo capaz de moldar os lugares e o comportamento das pessoas. Ela estabelece

[...] um conjunto de ações que se interligam a outros fenômenos urbanos, interferindo e moldando a percepção que cada indivíduo passa a ter do espaço onde vive, estabelecendo novas texturas e morfologias no crescimento do tecido urbano (Francisco Filho, 2004, p. 27). 
Mas é preciso considerar, ainda, que

\begin{abstract}
Nenhum fator isolado pode explicar por que alguns indivíduos se comportam com violência em relação a outros e por que a violência prevalece em algumas comunidades e não em outras. Uma combinação de fatores que podem indicar a emergência da violência intervém em diferentes níveis. No nível individual, por exemplo, a impulsividade sem autocontrole e o abuso de álcool e drogas são fatores de risco para todos os tipos de violência. No que diz respeito à família, a falta de habilidade no exercício da paternidade ou da maternidade é fator de risco para o abuso contra a criança [...], a ampla desigualdade entre ricos e pobres, o acesso fácil às armas e a aceitação social da violência podem prover campo fértil para a violência. A fim de impedir a violência, é necessário intervir em todos esses níveis (Pinheiro; Almeida, 2003, p.19).
\end{abstract}

A Geografia tem se preocupado com o estudo da violência, sobretudo devido aos impactos proporcionados por ela ao espaço e à cotidianidade da população. Queiroz (2002, p. 98) declara que "A violência que atinge as cidades brasileiras deixou de ser um fenômeno localizado e ganhou status de problema nacional". As pessoas não se conhecem e pouco se comunicam. Isolaram-se nos condomínios fechados, nos apartamentos, nas casas repletas de sistema de segurança, aparatos nem sempre eficazes. A criminalidade violenta, dessa forma, atua diretamente no cotidiano das cidades, regulando o modo de vida e o comportamento das pessoas e segregando as populações, quer por escolha deliberada ou por imposição socioeconômica.

\title{
CARACTERIZAÇÃO DOS CRIMES VIOLENTOS EM UBERLÂNDIA-MG
}

Entre 1999 e 2010, a cidade de Uberlândia registrou um total de 67.760 crimes violentos consumados. Desse total, 67.578 (99,73\%) totalizaram as ocorrências de estupros (418 casos), homicídios (839 casos) e roubos (66.321 casos), tendo este último apresentado o maior destaque, com $97,88 \%$ do total de crimes verificados. Os demais casos, perfazendo 182 eventos $(0,27 \%)$, representaram os crimes de extorsão mediante sequestro, latrocínio, sequestro e cárcere privado.

Os crimes violentos encontram-se presentes em todo o espaço urbano de Uberlândia, destacando-se em algumas áreas específicas: no Centro, as ocorrências de roubos (4.890 casos) e no São Jorge, os homicídios (62 casos) e os estupros (40 casos), além dos bairros adjacentes a estes, que também sofrem a influência da criminalidade violenta incidente nestes bairros.

Análise dos roubos 
Além do Centro, outros bairros apresentaram destaque nas ocorrências de roubos: Santa Mônica (4.669), Nossa Senhora Aparecida (4.049), Martins (3.205), Brasil (2.707), Tibery (2.496) e Presidente Roosevelt (2.436) (Figura 1). Dentre as modalidades de roubos, as três que mais se destacaram foram: a transeunte (36.139), de veículo automotor (7.007) e a prédio comercial (6.110). Essas três modalidades somaram 49.256 roubos, totalizando $74,27 \%$ dos casos registrados no período. Deste total, 31.010 roubos foram à mão armada, representando 62,96\% dos casos.

\section{Figura 1 - Cidade de Uberlândia. Roubos em números absolutos: 1999-2010}

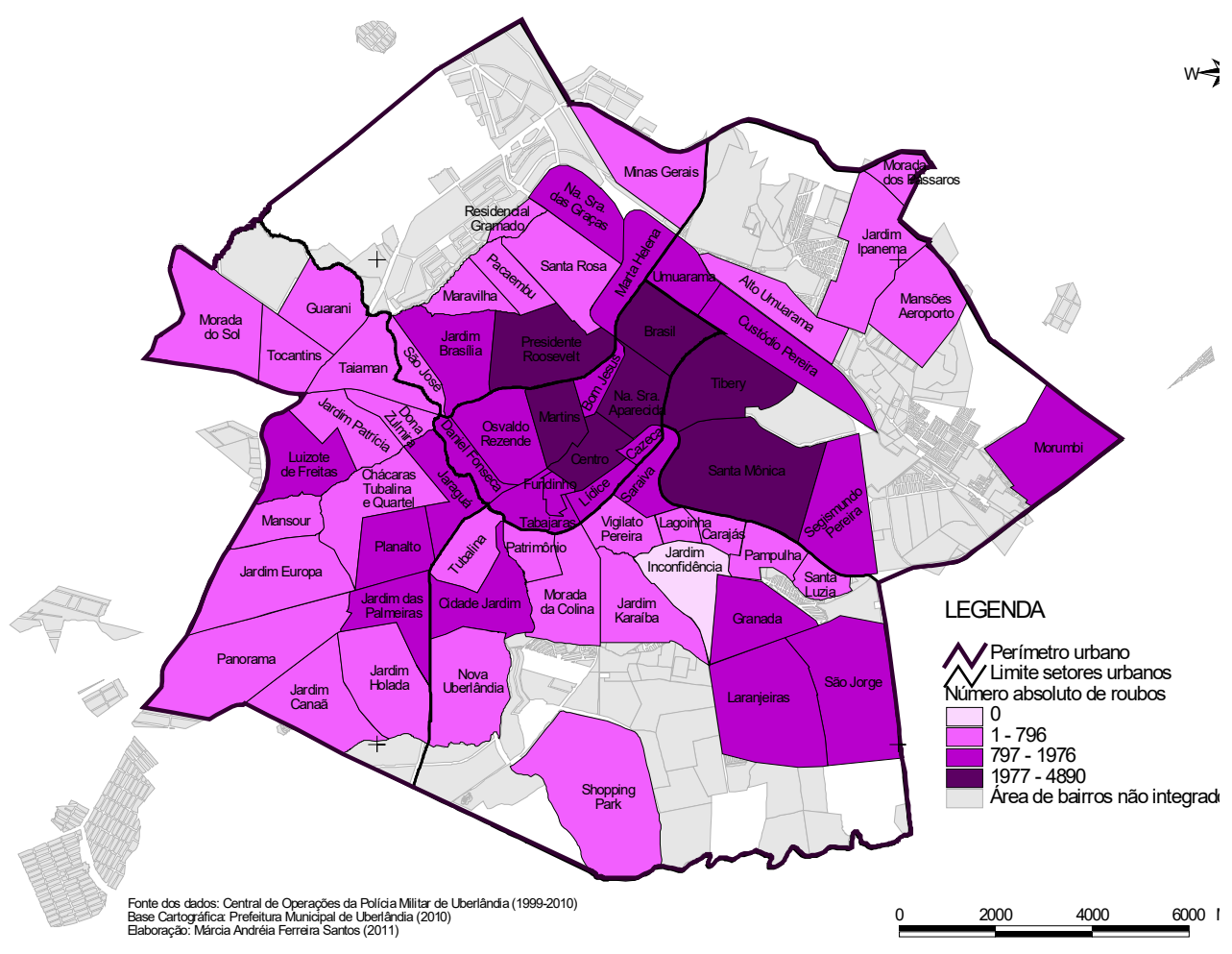

As ações de prevenção aos roubos são muito específicas para cada modalidade. Para roubos a transeunte, há uma grande participação da vítima no processo, principalmente no que se refere ao cuidado quando se transita pelas vias: deve-se evitar transportar elevadas quantias em dinheiro, objetos de alto valor econômico ou falar ao celular, e quando realizar saques em caixas eletrônicos, observar toda a movimentação de pessoas próximas, e fora dos bancos. Essas são algumas dicas passadas pela Polícia Militar à população. Acrescenta-se a isso as condições do espaço, que devem ser observadas pelo transeunte, e algumas devem ser, se possível, evitadas, como trafegar por locais pouco iluminados, e em lugares ermos, à noite, quando as condições favorecem a ocorrência de roubos e de outros crimes, como o estupro, por exemplo (Misse, 2007; Felson; Clarke, 1998; Cohen; Felson, 1979). 
Os roubos de veículo automotor podem ser evitados utilizando-se de equipamentos de segurança específicos, como alarmes e travas. Mas também alguns cuidados, por parte dos donos, podem minimizar os riscos, como observar o ambiente próximo à residência ao sair ou chegar, com o objetivo de verificar a presença de pessoas estranhas, dar preferência por estacionar em locais apropriados, tanto nas vias quanto em espaços privados próprios para esta finalidade, evitando permanecer dentro do veículo com ele parado. Estas são algumas ações que os próprios proprietários podem tomar para evitar a oportunidade de vitimização (Felson; Clarke, 1998).

O roubo a prédio comercial é evitado com a utilização de equipamentos de segurança patrimonial, como os alarmes, trancas, guardas e vigilantes. Entretanto, nem todos os estabelecimentos possuem esse tipo de estratégia de prevenção, o que os tornam vulneráveis à ação dos criminosos. Mas todo esse instrumento de combate ao crime também não é suficiente para evitar totalmente os roubos, pois os ladrões possuem suas formas próprias de agir, e sabem identificar as condições favoráveis para a sua atuação.

Com o objetivo de conter as ocorrências de roubos no Setor Central da cidade, foram instaladas, em 2008, 72 câmeras de videomonitoramento, numa parceria entre a Polícia Militar e os comerciantes locais, constituintes do projeto denominado "Olho Vivo. Esta estratégia teve por objetivo prevenir e reprimir o roubo, bem como outros atos violentos (Corrêa, 2008a; Silva, 2010). Essa ação apresentou resultados positivos logo após ter sido implantada, com a diminuição de roubos a veículos automotores, transeuntes e ao comércio, apresentando, também, queda nas ocorrências de estupros, homicídios, sequestros e cárcere privado, latrocínio e extorsões mediante sequestro. Mas, apesar desse resultado, levou, também, à migração do crime para áreas adjacentes ao local monitorado (Corrêa, 2008b; Fernandes, 2009).

A implantação das câmeras de videomonitoramento permitiram a diminuição da criminalidade violenta no Centro e nas áreas adjacentes, como também

[...] aumentou a sensação de conforto e segurança das pessoas que ali transitam, dos empresários que têm nestes locais os seus empreendimentos, e hoje, inclusive, é fonte, de anseios por vários outros cidadãos que procuram os órgãos públicos no sentido da gente ter aumentado realmente essa ferramenta que tem para nós trazido, mais uma vez, resultados que são significativos (Crovato, 2009; Em entrevista concedida à Prefeitura Municipal de Uberlândia).

As áreas centrais das grandes cidades recebem, diariamente, muitas pessoas que se deslocam para lá com a finalidade de realizarem as mais diversas atividades. Sendo assim, a quantidade de pessoas que circulam no local é bastante elevada; logo, a probabilidade de incidência de roubos, bem como de outros crimes, também aumenta. 
Em suma, a migração de crimes no espaço urbano é uma realidade quando intervenções com vistas à minimização dos casos são executadas. No caso particular dos crimes contra o patrimônio, que estão relacionados a outros eventos, como o tráfico e uso de drogas, os latrocínios e o porte ilegal de arma de fogo, as ações de segurança devem ser estabelecidas visando, também, a diminuição desses crimes. Neste sentido, ressalta-se a importância da intersetorialidade na implementação dessas ações.

\section{ANÁLISE DOS HOMICÍDIOS}

Os homicídios incidiram sobretudo no bairro São Jorge, onde foram registrados 62 casos; entretanto, o Morumbi, Tocantins e Tibery também se destacaram, com 55, 40 e 38 casos, respectivamente (Figura 2).

\section{Figura 2 - Cidade de Uberlândia. Homicídios em números absolutos: 1999-2010}

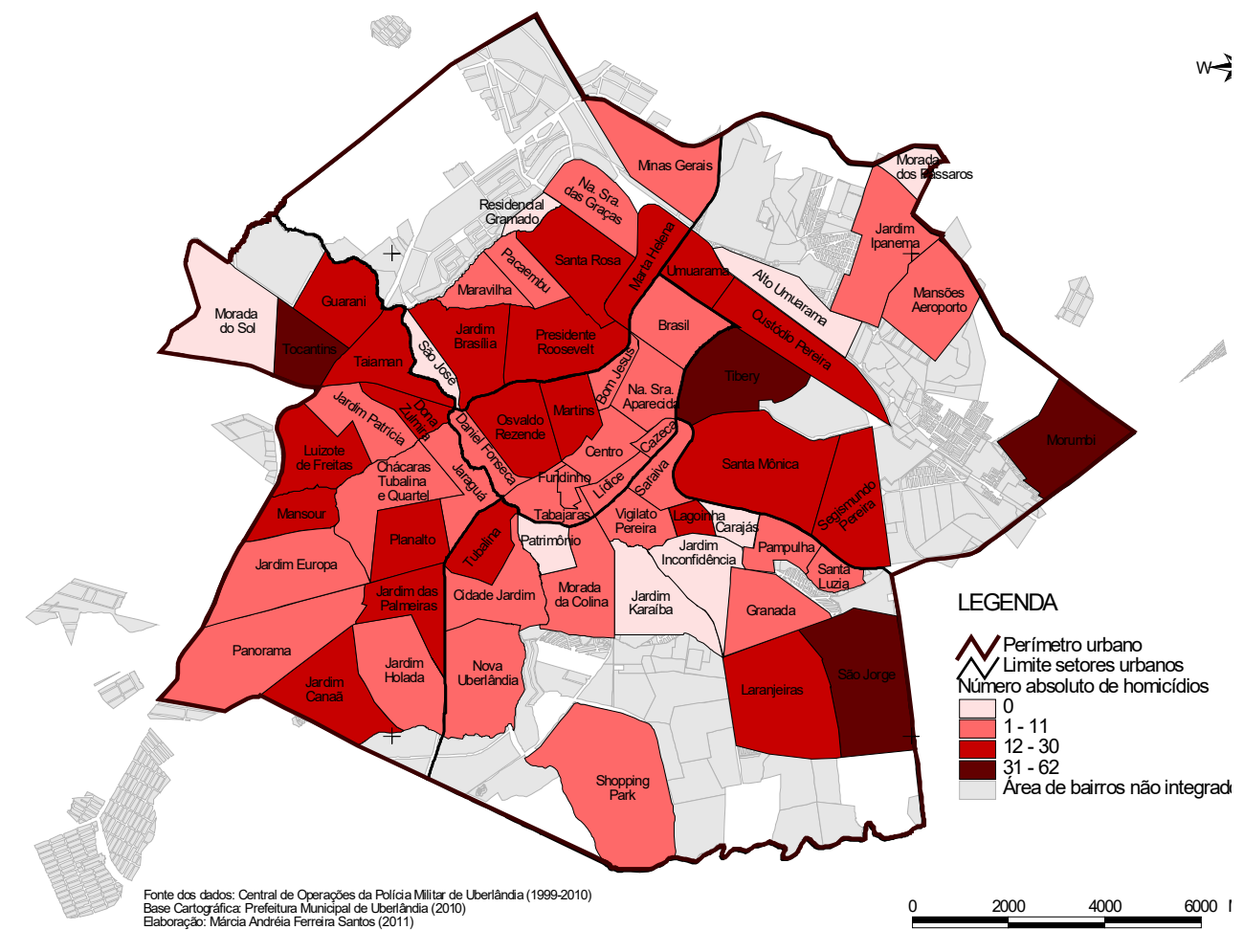

É importante destacar que os bairros onde incidiram as maiores ocorrências de homicídios - São Jorge, Morumbi, Tocantins e Tibery - são, de igual modo, os locais onde também se verificaram registros elevados de tráfico de drogas, que, por sua vez, condiciona à ocorrência de diferentes crimes perpetrados com vistas à manutenção desse mercado ilegal. Sobre isso, Souza (2000) declara que 
Embora o tráfico de drogas e a criminalidade urbana violenta não sejam sinônimos - pois nem o tráfico precisa sempre e em todas as instâncias da violência nem a criminalidade violenta, naturalmente, se reduz aos crimes vinculados com o tráfico -, é indiscutível que a dinâmica da violência urbana passou, nas duas últimas décadas, a estar fortemente marcada pelos efeitos diretos (guerra entre quadrilhas e entre estas e a polícia, "balas perdidas") e indiretos (empréstimo de armamentos de traficantes para criminosos comuns, delitos praticados por viciados etc.) (Souza, 2000, p. 53).

A tendência observada para os homicídios durante a semana revela que as ocorrências estão muito relacionadas aos estilos de vida dos indivíduos. Aos finais de semana, as pessoas ficam mais expostas e, portanto, predispostas a sofrerem algum agravo pelo fato de permanecerem mais tempo fora de casa praticando outras atividades, como as de lazer, o que pode favorecer as ocorrências. O mesmo pode ser dito quando se observa a distribuição dos homicídios segundo os horários de ocorrência, no qual se verificou um maior número de registros no período da noite e a madrugada.

Para conter o avanço dos homicídios, a Polícia Militar implantou nas áreas de risco a Patrulha de Prevenção a Homicídios (PPH), em conjunto com o Grupo Especializado em Policiamento de Áreas de Risco (GEPAR). A Patrulha de Prevenção a Homicídio atua, também, na estratificação de informações de crimes como lesão corporal, ameaças, disparos de armas de fogo, homicídios tentados e consumados, a partir de intervenções e visitas preventivas a endereços ou locais onde estão os infratores (Boente, 2012).

O Programa Fica Vivo é outra estratégia de combate aos homicídios. Foi implantado, inicialmente, em 2005, no bairro Morumbi, com o objetivo de combater e prevenir os homicídios. É destinado a adolescentes e jovens com idade entre 12 e 24 anos. É uma articulação de órgãos públicos e não-governamentais, com vistas à oferta de serviços de saúde, educação, assistência social e segurança pública; criação de oportunidades no campo da educação, cultura, lazer e profissionalização para a população-alvo; melhoria do policiamento comunitário e do GEPAR. Sua implantação permitiu a diminuição dos homicídios e roubos Morumbi; todavia, levou à migração da criminalidade para áreas que não possuem o programa ou onde não existem outras estratégias de segurança pública eficazes.

\section{ANÁLISE DOS ESTUPROS}

O estupro sempre representou a principal expressão de violência contra as mulheres, praticado, sobretudo, pelo homem (Chagas, 2009). Até meados de 2009, quando foi sancionada a Lei no 12.015, de 7 de agosto de 2009 (Brasil, 2009), o Código Penal Brasileiro previa os seguintes crimes contra a "liberdade sexual": estupro (art. 213); atentado violento ao pudor (art. 214); posse sexual mediante fraude (art. 215); atentado ao pudor mediante fraude (art. 216); e assédio sexual (art. 216-A).

te fraude (art. 216); e assédio sexual (art. 216-A). 
Com o vigor da Lei no. 12.015/2009 (Brasil, 2009), o conceito de estupro mudou e os artigos 213 e 214 do Código Penal se fundiram. O artigo 214, que descrevia o atentado violento ao pudor, foi revogado, e o seu texto incluído no artigo 213, que passou a ter a seguinte redação: "Constranger alguém, mediante violência ou grave ameaça, a ter conjunção carnal ou a praticar ou permitir que com ele se pratique outro ato libidinoso: pena - reclusão de 6 (seis) a 10 (dez) anos”. Essa, portanto, tornou-se a nova descrição legal do estupro e, assim, tanto a mulher quanto o homem podem ser vítimas desse crime, quando constrangidos, mediante violência física ou grave ameaça psicológica a praticar conjunção carnal ou qualquer ato libidinoso (Brasil, 2010).

Acrescenta-se que o artigo 216 do Código Penal ("atentado ao pudor mediante fraude") também foi revogado e o seu texto incorporado ao artigo 215, que antes se denominava "posse sexual mediante fraude" e agora: "violação sexual mediante fraude". Após a nova lei do estupro, os "crimes contra a liberdade sexual" passaram a ser os seguintes: estupro (art. 213); violação sexual mediante fraude (art. 215); e assédio sexual (art. 216-A). Além disso, a nova lei criou um capítulo denominado "Dos crimes contra vulnerável", sendo que no Capítulo II, Título VI estão previstas as seguintes figuras penais: “estupro de vulnerável” (art. 217-A)1, que consiste em “Ter conjunção carnal ou praticar outro ato libidinoso com menor de quatorze anos"; "induzimento de menor de 14 anos a satisfazer a lascívia de outrem" (art. 218)2; "satisfação de lascívia mediante a presença de criança ou adolescente" (art. 218-A)3: e "favorecimento da prostituição ou outra forma de exploração sexual de vulnerável“" (art. 218-B)4 (Brasil, 2010). Com essas alterações, todos os crimes previstos no Título VI são considerados violência sexual. É importante ressaltar que o antigo Título VI, referente aos "crimes contra os costumes", tem agora um novo nome: "Dos crimes contra a dignidade sexual".

Os estupros registrados pelo Centro de Operações da Polícia Militar (COPOM) em Uberlândia passaram a enquadrar-se na Lei ${ }^{\circ}$. 12.015, logo após ter sido sancionada. Também por esta razão, verifica-se que os números de ocorrência em 2009 e 2010 foram maiores do que nos anos anteriores. Em relação à distribuição espacial, o São Jorge foi o bairro que apresentou o maior número de casos de estupros. Além dele, destacaram-se o Santa Mônica (24), Jardim Brasília (16), Martins (16), Morumbi (16), Segismundo Pereira (15), Tibery (15) e Tocantins (14) (Figura 3). 
Figura 3 - Cidade de Uberlândia. Estupros em números absolutos: 1999-2010.

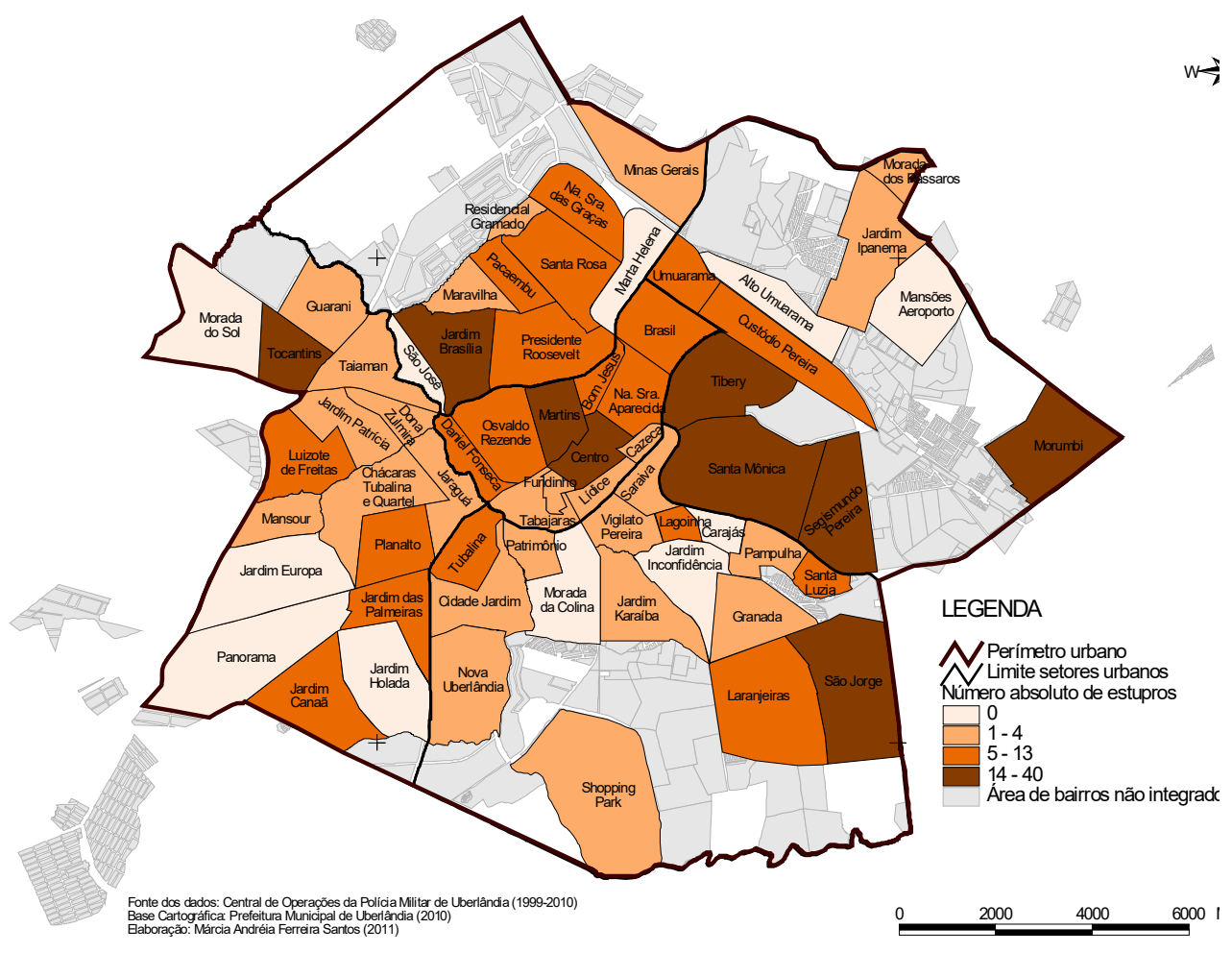

O estupro é um crime de difícil prevenção, mas não impossível. Difícil, pelo fato de envolver um grupo vulnerável, constituído de crianças e adolescentes, cujo agressor é, geralmente, uma pessoa próxima, quer por laços de amizade ou parentesco, havendo, consequentemente, confiança entre as partes. Tais características não são próprias do Brasil. Giffin (1994) declara que em algumas nações, como nos Estados Unidos, o risco de uma mulher sofrer um estupro até os 18 anos é de 62\% e, no Canadá, até os 17 anos, 25\%. O referido autor declara que, em Lima, capital do Peru, um estudo com mães adolescentes revelou que $90 \%$ das mães com idade entre 12 e 16 anos haviam sido estupradas, em sua maioria, pelo pai, padrasto ou parente próximo. Na Costa Rica, uma instituição voltada para o atendimento de mães adolescentes declarou que 95\% das grávidas com menos de 15 anos eram vítimas de incesto.

As ações de prevenção de novos casos de estupro, bem como de reincidência têm sido estabelecidas, especialmente, pela área da saúde. Assim, o Ministério da Saúde, através da Secretaria de Atenção à Saúde/Área Técnica de Saúde da Mulher, tem atuado em duas estratégias específicas: 1) Capacitar e equipar os serviços a diagnosticar os casos de violência e promover a assistência adequada; 2) Ampliar e desenvolver os serviços especiali- 
zados ou de referência. Vale ressaltar que a oferta desses serviços permite a crianças, adolescentes e mulheres o acesso imediato aos cuidados de saúde, à prevenção de doenças sexualmente transmissíveis e à gravidez indesejada. Incluem aqui os serviços voltados para a vítima de violência sexual, que pode ser atendida com as seguintes ações e intervenções: apoio psicossocial, anticoncepção de emergência, doenças sexualmente transmissíveis não virais, hepatites virais, infecção pelo HIV, acompanhamento laboratorial, gravidez decorrente de violência sexual e procedimentos de interrupção de gravidez (Brasil, 2005). Além destes serviços de saúde, Uberlândia dispõe de ONGs, como o SOS Mulher Família, a Casa Abrigo Travessia, os Conselhos tutelares e as Delegacias Especializadas em Atendimento à Mulher (DEAM).

\section{CONSIDERAÇÕES FINAIS}

O estudo dos crimes violentos em Uberlândia possibilitou alguns questionamentos, como: Quais as causas para essa configuração espacial do crime, na cidade, e que fatores sociais, culturais, econômicos e políticos contribuem para essa caracterização? A criminalidade é um fenômeno complexo e multifacetado, cujas causas são, também, diversas, e perpassam por todas as questões que envolvem e constituem a sociedade. Felix (1996) comenta, que dentre as teorias que buscam explicar as causas da manifestação espacial da criminalidade violenta, destacam-se aquelas de fundamentação sociocultural, que pressupõem que quando o sucesso econômico se torna improvável, a privação pode levar à busca de aquisição de bens de forma ilícita. Outro fator citado pela referida autora está relacionado à aglomeração de pessoas nos centros urbanos, que ressalta a desigualdade social, condicionando à prática criminal como resposta à oposição entre o desejo de posse material e as possibilidades reais de realização.

Diniz e Batella (2006) salientam que o grau de deterioração das estruturas físicas das cidades mais desenvolvidas como também a intensa mobilidade espacial da população enfraquece a coesão social através do confronto entre valores culturais e contribuem para a incidência da criminalidade. É importante considerar que há espaços urbanos que embora as características supracitadas estejam presentes, a incidência criminal é baixa, revelando que a ocorrência de crimes depende de uma série de elementos que, combinados em certa proporção, confluem para que tal fenômeno ocorra.

Pequenas atitudes dos moradores podem diminuir as chances de vitimização, como a aproximação entre os vizinhos. As autoridades de segurança pública recomendam que 
se mantenha um relacionamento maior com as pessoas que residem próximas, pois elas podem ajudar a manter a vigilância da residência em horários nos quais o dono se encontra fora minimizando, dessa forma, as oportunidades que possam vir a favorecer a prática de um roubo a residência, por exemplo. Ressalta-se, ainda, que a parceria entre comunidade e polícia tem apresentado bons resultados, sobretudo no que se refere à denúncia anônima, pois apenas a ronda diária não é capaz de manter a segurança.

Outro fator diz respeito ao número de denúncias acerca da criminalidade, que quando aumentam, acabam por pressionar os órgãos responsáveis para que elaborem estratégias que visem minimizar as ocorrências criminais. Muitas vítimas não denunciam a violência que sofreram porque sabem que o agressor pode não ser punido ou por falta de provas, ou por morosidade da Justiça. Existe, ainda, o agravante do medo de reincidência ou de represália por parte dos próprios bandidos, que permanecendo em liberdade podem perseguir a vítima para se vingar por ter sido denunciado.

\section{REFERÊNCIAS}

1. BOENTE, Fernando. Em janeiro foi registrado um homicídio a cada dois dias. Correio de Uberlândia, Uberlândia, 31 jan. 2012. http://www.correiodeuberlandia.com.br. Acesso em: 22 fev. 2012.

2. BRASIL. Ministério da Saúde. Secretaria de Atenção à Saúde. Departamento de Ações Programáticas Estratégicas. Aspectos jurídicos do atendimento às vítimas de violência sexual: perguntas e respostas para profissionais de saúde. Brasília: Editora do Ministério da Saúde, 2010. 48p. (Série F. Comunicação e Educação) (Série Direitos Sexuais e Direitos Reprodutivos; Caderno n.7).

3. L__ Lei n. 12.015, de 7 de agosto de 2009. Altera o Título VI da Parte Especial do DecretoLei $\mathrm{n}^{\circ}$ 2.848, de 7 de dezembro de 1940 - Código Penal, e o art. $1^{\circ}$ da Lei $\mathrm{n}^{\mathrm{o}}$ 8.072, de 25 de julho de 1990, que dispõe sobre os crimes hediondos, nos termos do inciso XLIII do art. $5^{\circ}$ da Constituição Federal e revoga a Lei $\mathrm{n}^{\circ} 2.252$, de $1^{\circ}$ de julho de 1954, que trata de corrupção de menores. Brasília, DF, 2009.

4. _____. Ministério da Saúde. Secretaria de Atenção à Saúde. Departamento de Ações Programáticas Estratégicas. Área Técnica de Saúde da Mulher. Prevenção e Tratamento dos Agravos Resultantes da Violência Sexual contra Mulheres e Adolescentes. Norma Técnica, $2^{\text {a }}$ ed. atual e ampliada. Brasília: Ministério da Saúde, 2005. 73p.

5. Código Penal. Decreto-Lei no 2.848, de 7 de dezembro de 1940. Rio de Janeiro, 7 dez. 1940. 
6. CHAGAS, José Ricardo. A nova lei do estupro: o homem e a mulher como sujeitos ativo e passivo e o abrandamento punitivo. Revista Jus Navigandi, Teresina, ano 14, n.2241, 20 ago. 2009. Disponível em: http://jus.uol.com.br/revista/texto/13359/a-nova-lei-do-estupro. Acesso em: 23 nov. 2010.

7. COHEN, Lawrence; FELSON, Marcus. Social change and crime rate trends: a routine activity approach. American Sociological Review, University of Illinois, v.44, p.588-608, August 1979.

8. CORRÊA, Gleide. Cidade terá 72 câmeras de vigilância. Sistema Olho Vivo começa a monitorar as ruas 24 horas. Correio de Uberlândia, Uberlândia, 02 jun. 2008. Disponível em: http://www. correiodeuberlandia.com.br. Acesso em: 21 out. 2008a.

9. Câmeras reduzem crimes pela metade. Roubos a pessoas, comércio e carros tiveram queda na região monitorada. Correio de Uberlândia, Uberlândia, 02 ago. 2008. Disponível em: http://www.correiodeuberlandia.com.br. Acesso em: 21 out. 2008b.

10. COPOM - Centro de Operações da Polícia Militar. Assessoria de estatística e geoprocessamento. Uberlândia: COPOM, 2011.

11. CROVATO, Dilmar. Coronel Dilmar Crovato fala sobre parceria entre Prefeitura de Uberlândia e Polícia Militar. Uberlândia: Prefeitura Municipal de Uberlândia, 30 dez. 2009. Entrevista concedida à Prefeitura Municipal de Uberlândia.

12. DINIZ, Alexandre Magno Alves; BATELLA, Wagner Barbosa. Abordagens espaciais no estudo da criminalidade violenta nas cidades médias mineiras. In: II SIMPÓSIO INTERNACIONAL SOBRE CIDADES MÉDIAS - DINÂMICA ECONÔMICA E PRODUÇÃO DO ESPAÇO, 2006, Uberlândia. Anais... Uberlândia: UFU, 2006. v. único. p.1-20.

13. ESTEVES, Alina Isabel Pereira. A criminalidade na cidade de Lisboa: a geografia da insegurança. Lisboa: Edições Colibri, 1999. 214p.

14. FELIX, Sueli Andruccioli. Crime, medo e percepções de insegurança. Perspectivas, São Paulo, v. 36, p. 155-173, jul./dez. 2009.

15. ___ Geografia do Crime. Revista de Geografia, São Paulo, v. 13, p. 145-166, 1996.

16. FELSON, Marcus; CLARKE, Ronald V. “Opportunity makes the thief. Practical theory for crime prevention”. London: Research, Development and Statistics Directorate, 1998. 36p. (Police Research Series, paper 98).

17. FERNANDES, Arthur. Crimes violentos caem em mais de $50 \%$ em regiões vigiadas. Correio de Uberlândia, Uberlândia, 24 jul. 2009. Caderno Cidade, B3. Disponível em: http://www. correiodeuberlandia.com.br. Acesso em: 20 mar. 2010.

18. FERREIRA, Ignez Costa Barbosa; PENNA, Nelba Azevedo. Território da violência: um olhar geográfico sobre a violência urbana. Revista GEOUSP - Espaço e Tempo, São Paulo, n.18, p.155-168, 2005.

19. FRANCISCO FILHO, Lauro Luiz. Distribuição espacial da violência em Campinas: uma análise por geoprocessamento. 2004. 170f. Tese (Doutorado em Geografia) - Instituto de Geociências - Departamento de Geografia, Universidade Federal do Rio de Janeiro, Rio de Janeiro, 2004. 
20. GIFFIN, Karen. Violência de gênero, sexualidade e saúde. Cadernos de Saúde Pública, Rio de Janeiro, v. 10, supl.1, p.146-155, 1994

21. MASSENA, Rosa Maria Ramalho. Distribuição espacial da criminalidade violenta na região metropolitana do Rio de Janeiro. Revista Brasileira de Geografia, Rio de Janeiro, v.48, n.3, p.285-330, jul./set., 1986.

22. MISSE, Michel. Explicando a violência urbana e a criminalidade no Brasil: um mapa das posições teóricas e metodológicas em disputa. In: ZANOTELLI, Cláudio Luiz; RAIZER, Eugênia Célia; VALADÃO, Vanda de Aguiar. Violência e contemporaneidade: dimensões das pesquisas e impactos sociais. Vitória: Grafita Gráfica e Editora - NEVI, 2007. p.31-36.

23. MORAIS, Régis. O que é violência urbana. São Paulo: Brasiliense, 1990. 113p.

24. PINHEIRO, Paulo Sérgio; ALMEIDA, Guilherme Assis de. Violência urbana. São Paulo: Publifolha, 2003. 88p.

25. QUEIROZ, L. da S. A cidade sitiada: da violência consentida ao medo com sentido. In: PONTUCHKA, N. N.; OLIVEIRA, A. V. (org.). Geografia em Perspectiva, São Paulo: Contexto, 2002. p. 97-106.

26. SILVA, Frederico. Centros comerciais e DI terão câmeras. Correio de Uberlândia, 26 nov. 2010. Caderno Cidade e Região, A8. Disponível em: http://www.correiodeuberlandia.com.br. Acesso em: 19 jul. 2010.

27. SOUZA, Marcelo José Lopes de. O desafio metropolitano: um estudo sobre a problemática socioespacial nas metrópoles brasileiras. Rio de Janeiro: Bertrand Brasil, 2000. 368p.

28. TUAN, Yi-Fu. Paisagens do medo. São Paulo: Editora UNESP, 2005. 376p.

Artigo recebido em 18 de janeiro de 2016.

Artigo aceito em 04 de novembro de 2016. 